\title{
ANTIOXIDANT CAPACITY, TOTAL PHENOLIC COMPOUNDS AND FATTY ACIDS COMPOSITION IN WALNUT OIL AND BAGASSE PELLETS PRODUCED AT DIFFERENT PARAMETERS OF THE SCREW PRESS
}

\author{
Tomáš Kiss¹, Vladimír Mašán², Pavel Híc ${ }^{3}$ \\ ${ }^{1}$ Department of Fruit Growing, Faculty of Horticulture, Mendel University in Brno, Zemědělská 1, 61300 Brno, \\ Czech Republic \\ ${ }^{2}$ Department of Horticultural Machinery, Faculty of Horticulture, Mendel University in Brno, Zemědělská 1, \\ 61300 Brno, Czech Republic \\ ${ }^{3}$ Department of Post-Harvest Technology of Horticultural Products, Faculty of Horticulture, Mendel University \\ in Brno, Zemědělská 1, 61300 Brno, Czech Republic
}

Link to this article: https://doi.org/10.11118/actaun202068030519

Received: 23. 5. 2018, Accepted: 8. 6. 2020

To cite this article: KISS TOMÁŠ, MAŠÁN VLADIMÍR, HÍC PAVEL. 2020. Antioxidant Capacity, Total Phenolic Compounds and Fatty Acids Composition in Walnut Oil and Bagasse Pellets Produced at Different Parameters of the Screw Press. Acta Universitatis Agriculturae et Silviculturae Mendelianae Brunensis, 68(3): 519-527.

\begin{abstract}
Different rotational speeds and nozzle diameters of screw press were used to process walnut kernels. To evaluate the influence of pressing conditions on the quality of walnut oil and bagasse pellets the oil pressing temperature, yield of oil, total phenolic compounds, antioxidant capacity and fatty acid composition were measured. The results show that the pressing at different conditions affected the antioxidant capacity and TPC of either bagasse pellets and pressed oil. Higher values of antioxidant capacity and TPC were measured in bagasse pellets than in pressed oils. Higher amount of pressed oil was yielded by using lower nozzle diameter, however, by lowering the nozzle diameter the oil pressing temperature was rising, which affected the fatty acids. Positive correlations with oil pressing temperatures were calculated at saturated fatty acids, while the correlation coefficients of polyunsaturated fatty acids were positive, but not significant. Monounsaturated fatty acids were negatively affected by higher oil pressing temperatures showing, that monounsaturated fatty acids were more susceptible to higher temperatures than polyunasturated and saturated fatty acids.
\end{abstract}

Keywords: antioxidant capacity, total phenolic compounds, fatty acids, walnut oil, bagasse pellets, screw press

\section{INTRODUCTION}

Walnut kernels are consumed worldwide, fresh or as an industrially modified product or their secondary products as an ingredient in the food. In 2013 walnut trees were grown on area of 1 million hectares worldwide. The biggest producers are the USA and China (FAO, 2016).
The most valuable parts of the walnut tree are the kernels. Regular consumption of walnuts reduces the risk of diabetes (Kendall et al., 2011), has positive effect on brain function (Hou et al., 2014) and reduces the amount of cholesterol in the blood (Kodad et al., 2016; Uzunova et al., 2015; Avanzato, 2010; Park et al., 2008). 
Walnut kernels have high oil content varying from 52 to 72\% (Poggetti et al., 2017; Slatnar et al., 2015; Labuckas et al., 2014; Martínez et al., 2006; Zwarts et al., 1999). One of the uses of walnut kernels is the production of edible oil, which has high positive sensory properties by consumers and is a well known nutrient-rich food mainly due to its profile of fatty acids with antioxidant capacity and phenolic compounds (Burg et al., 2017; Slatnar et al., 2015; Özcan, 2009). Walnuts have elevated levels of positive omega- 6 and omega- 3 fatty acids. Contained phenolic compounds are significant constituents owing to their scavenging competence on free radicals (Kaur et al., 2015; Slatnar et al., 2015).

Oil from walnut kernels can be produced by three technologies, mechanical extraction (pressed oil), chemical or solvent extraction and supercritical $\mathrm{CO}_{2}$ extraction (Singh and Bargale, 2000). The extraction by mechanical screw presses is typical for lower proportion of collected oil, which on the other hand is high-quality and contain bioactive compounds (Ezeh et al., 2016; Ling et al., 2016; Sena-Moreno et al., 2016; Wang, 2016; Mridula et al., 2015; Savoire et al., 2013).

The yield of oil from kernels by pressing is approximately $46 \%$, whereas the rest, around, $12 \%$ of oil stays in the bagasse pellets. Bagasse pellets are due to oil remainings and other biologically active compounds used, for example, in food industry for flour production (Bakkalbasi et al., 2015).

The quality and the composition of positive substance depends on gentle and fast pressing process, pressing temperature and avoiding of photo-oxidative degradation (Slatnar et al., 2015), however, Gharibzahedi et al. (2013) concluded that the fatty acid content was not influenced by extraction method.

The aim of the presented study was to evaluate the influence of different parameter settings of screw press on the quality, namely content and composition of fatty acids, antioxidant capacity and total phenolic content of pressed oil and bagasse pellets.

\section{MATERIALS AND METHODS}

\section{Walnut Kernels}

Walnut kernels originating in the Czech Republic were purchased in the supermarket chain, mixed together vacuum-packed and stored at $4^{\circ} \mathrm{C}$ in dark place. Prior pressing, the water content in the kernels was assessed $(2.95 \pm 0.21 \%)$. Kernels were ground in a stainless-steel mill to the fraction of the size from $0 \mathrm{~mm}$ to $6 \mathrm{~mm}$. Then, the material was pressed.

\section{Screw Press Parameters}

The screw press type UNO FM 3F (Farmet a. s., Česká Skalice, Czech Republic) was used for experimental measurements. This model is suitable for pressing all kinds of oilseeds. The drive is configured for three-phase voltage with variable speed of the main drive using a frequency converter, which enables better optimization of pressing parameters. The press components are: an electric motor $(1.5 \mathrm{~kW}$ power), transmission, pressing device, motor starter and frequency converter (allows precise adjustment of revolutions per minute - rpm). The screw rotation speed was adjusted on $30,50,70$ and $90 \mathrm{rpm}$. The pressing device components were: a matrix, $220 \mathrm{~mm}$ screw, head, heating mantle, nozzle holder and nozzles with different diameters (6 mm, $8 \mathrm{~mm}$ and $10 \mathrm{~mm}$ ). The variants were then combinations of different rotational speeds (30, 50, 70 and $90 \mathrm{rpm}$ ) and different nozzle diameters (6 $\mathrm{mm}, 8 \mathrm{~mm}$ and $10 \mathrm{~mm}$ ).

\section{Oil Temperature}

The oil temperature was measured directly on the press head by Testo 176 T4 - Temperature data logger (Testo SE \& Co. KGaA, Glen Marais, Republic of South Africa) with stainless steel food probe.

\section{Determination of the Total Fat Content in the Walnut Kernels and Bagasse Pellets}

To determine the total fat content, the Soxhlet extractor with hexane as a solvent was used. Samples of kernels were taken immediately prior to the oil extraction and the bagasse pellets were taken directly after the pressing. The samples were grinded by the IKA MF 10 basic (IKA-Works, Staufen, Germany) grinder using the $3 \mathrm{~mm}$ sieve. Emphasis was always taken on precise cleaning of the grinder in order to avoid distortion of the results. The temperature of the extraction mixture was kept by the heating mantle closely around the boiling point of hexane $\left(70^{\circ} \mathrm{C}\right)$. Extraction was carried out for 8 hours. Subsequently, the hexane was evaporated on the vacuum evaporator IKA RV 10 Control (IKAWorks, Staufen, Germany) at the pressure of $200 \mathrm{kPa}$ until the hexane was evaporated. After that, the pressure was lowered down to $60 \mathrm{kPa}$ for another 2 hours at the constant temperature of $40^{\circ} \mathrm{C}$. The weight of total fat was then measured by KERN EG 2200-2NM (Kern \& Sohn, Balingen, Germany).

\section{Analysis of Fatty Acids}

The preparation for fatty acids analysis was performed by transesterification. The oil samples from pressed oil, oil extracted from bagasse pellets or kernels was dissolved in $2 \mathrm{ml}$ of isooctane and homogenized in ultrasound. After adding $2 \mathrm{ml}$ of methanol sodium, the mixture was heated under condenser for 5 minutes. Subsequently, $2 \mathrm{ml} \mathrm{BF}$ was added (through the cooler) and the mixture was heated again under the same condenser for another 5 minutes. After that, $2 \mathrm{ml}$ of isooctane was added to the mixture, shook and left for 1 minute to settle down. At the very end, $5 \mathrm{ml}$ of saturated sodium chloride solution was added. 
The analysis of fatty acids was performed on the gas chromatograph HP 4890D (Hewlett Packard, USA) with a flame ionizing detector (GC-FID). The separation was performed on column DB$23(60 \mathrm{~m} \times 0.25 \mathrm{~mm} \times 0.25 \mu \mathrm{m})$. Every sample was measured in triplicates.

\section{Total Phenolic Compounds (TPC) and Antioxidant Capacity (DPPH Radical Scavenging)}

The preparation to determine the antioxidant capacity and total phenolic compounds in kernels and each sample of pressed oil and bagasse pellets was as follows: $0.5 \mathrm{~g}$ of sample was weighed while and extracted into $7.5 \mathrm{ml}$ of $50 \%$ methanol, sonicated for $60 \mathrm{~min}$ at the room temperature and then centrifuged at $16100 \mathrm{~g}$ for $20 \mathrm{~min}$ at $4^{\circ} \mathrm{C}$. After centrifugation, the methanol phase was removed.

The analysis of antioxidant capacity was determined using 1,1-diphenyl-2-picrylhydrazyl (DPPH) and the test was performed on the spectrophotometer Boeco S-200 (Boeco, Hamburg, Germany) where the absorbance at the wavelength of $534 \mathrm{~nm}$ was measured. The result was calculated to mg of Trolox equivalent activity (TEA) per gram of sample. Every sample was measured in triplicates.

The analysis of total phenol content was performed on the spectrophotometer Boeco S-200 (Boeco, Hamburg, Germany) where the absorbance at the wavelength of $660 \mathrm{~nm}$ was measured. The result was calculated to mg of gallic acid equivalent (GAE) per gram of sample. Every sample was measured in triplicates.

\section{Statistical Analysis}

As determinations were done in triplicate the data were reported as means \pm standard deviation. Analysis of variance (ANOVA) and Tukey's honestly significant difference (HSD) tests were conducted to determine the differences with the statistical significance at $\mathrm{p} \leq 0.05$. Further correlation coefficients were calculated between the content of fatty acids and oil pressing temperatures with the statistical significance at $\mathrm{p} \leq 0.05$. Statistical analyses were performed by the software Statistica 12.0 (StatSoft Inc., Tulse, USA).

\section{RESULTS AND DISCUSSION}

\section{Yield of Oil and Oil Temperature}

The total oil content was $0.70 \mathrm{~kg}$ oil $/ \mathrm{kg}$ kernels (Tab. I). The oil yield of different nozzle diameters and rotational speed ranged from 0.12 to $0.41 \mathrm{~kg}$ oil/kg kernels. The highest yields were performed by the $6 \mathrm{~mm}$ nozzle diameter $(0.33-0.41 \mathrm{~kg}$ oil $/ \mathrm{kg}$ kernels) while the lowest yields were performed by the $10 \mathrm{~mm}$ nozzle diameter $(0.12-0.28 \mathrm{~kg}$ oil $/ \mathrm{kg}$ kernels). The rotational speed influenced the yield as well, showing higher yields of oil at lower speeds and lower yield at higher speeds. The lowest yield was then performed by using $10 \mathrm{~mm}$ nozzle diameter at $90 \mathrm{rpm}(0.12 \mathrm{~kg}$ oil $/ \mathrm{kg}$ kernels $)$ and the highest yield by using $6 \mathrm{~mm}$ nozzle diameter at $30 \mathrm{rpm}$ (0.41 kg oil/kg kernels).

The oil temperature during pressing reached 38.33 to $63.67^{\circ} \mathrm{C}$ (Tab. I). Again the highest temperatures were recorded when the $6 \mathrm{~mm}$ nozzle diameter was used. At other nozzle diameters, the temperatures were similar and ranged from 38.33 to $55.33^{\circ} \mathrm{C}$. Results show, that at $90 \mathrm{rpm}$ the oil temperatures were the lowest, however, at $6 \mathrm{~mm}$ nozzle diameter, the data for $90 \mathrm{rpm}$ are missing as the press could not process the kernels.

\section{Total Phenolic Compounds (TPC)}

The TPC of kernels was $140.59 \pm 4.59 \mathrm{mg}$ of gallic acid equivalent (GAE)/g (Tab. I). After pressing, all oils had lower TPC than of the kernels, while all bagasse pellets, except for $10 \mathrm{~mm}$ nozzle diameter at $30 \mathrm{rpm}$, had higher TPC showing that the phenolic compounds were concentrated predominantly in the solid phase. According to Slatnar et al. (2015), the majority of phenolic compounds of walnut kernels are located in the skin of the kernel.

The results also showed that the TPC in pressed oils was increasing with the rotational speed, where at all nozzle diameters the highest TPC was measured at oils produced at $90 \mathrm{rpm}$ or $70 \mathrm{rpm}$ at $10 / 8 \mathrm{~mm}$ and $6 \mathrm{~mm}$ nozzle diameter, respectively (Tab. I). The highest TPC had oil produced at $6 \mathrm{~mm}$ nozzle diameter at $90 \mathrm{rpm}(116.72 \pm 3.81 \mathrm{mg}$ GAE/g), while the TPC of oil pressed at $8 \mathrm{~mm}$ nozzle diameter at 30-70 rpm were zero (Tab. I).

There was no effect of rotational speed on the TPC in bagasse pellets. However, the highest TPC was measured in bagasse pellets produced by $6 \mathrm{~mm}$ nozzle diameter at $30 \mathrm{rpm}$ (203.88 $\pm 6.66 \mathrm{mg} \mathrm{GAE} / \mathrm{g})$ and the lowest by $10 \mathrm{~mm}$ nozzle diameter at $30 \mathrm{rpm}$ $(138.65 \pm 4.53 \mathrm{mg} \mathrm{GAE} / \mathrm{g})$ (Tab. I).

\section{Antioxidant Capacity (DPPH Radical Scavenging)}

The antioxidant capacity of kernels was $232.02 \pm 7.58 \mathrm{mg}$ Trolox equivalent activity (TEA)/g (Tab. I). After pressing, all oils had significantly lower antioxidant capacity than of the kernels and ranged from 46.51-50.59 mg TEA/g, with no significant difference between each other (Tab. I). There was no effect of rotational speed on the antioxidant capacity of oils.

The antioxidant capacity of bagasse pellets ranged from $205.58-241.16 \mathrm{mg}$ TEA/g (Tab. I). The antioxidant capacity of bagasse pellets produced at 8 and $10 \mathrm{~mm}$ nozzle diameter were lower, significantly only at the bagasse pellets produced at $10 \mathrm{~mm}$ nozzle diameter at $50 \mathrm{rpm}$, than the antioxidant capacity of the kernels. Higher antioxidant capacity than of the kernels was measured at bagasse pellets produced by $6 \mathrm{~mm}$ nozzle diameter, however with no significant differences (Tab. I). 
I: Values of oil yield, oil pressing temperature, antioxidant capacity and total phenolic content of pressed oil and bagasse pellets produced at different nozzle diameters and rotational speeds of a screw press

\begin{tabular}{|c|c|c|c|c|c|c|c|}
\hline \multirow{2}{*}{$\begin{array}{l}\text { Nozzle } \\
\text { diameter } \\
(\mathrm{mm})\end{array}$} & \multirow{2}{*}{$\begin{array}{c}\text { Rotational } \\
\text { speed } \\
(\mathrm{rpm})\end{array}$} & \multirow{2}{*}{$\begin{array}{c}\text { Yield } \\
\text { (kg oil/kg kernel) }\end{array}$} & \multirow{2}{*}{$\begin{array}{l}\text { Oil temp. } \\
\quad\left({ }^{\circ} \mathrm{C}\right)\end{array}$} & \multicolumn{2}{|c|}{$\begin{array}{l}\text { Antioxidant Capacity (DPPH) } \\
\text { (mg TEA/g) }\end{array}$} & \multicolumn{2}{|c|}{$\begin{array}{l}\text { Total Phenolic Content } \\
\text { (mg GAE/g) }\end{array}$} \\
\hline & & & & Pressed oil & Bagasse pellets & Pressed oil & Bagasse pellets \\
\hline $10 \mathrm{~mm}$ & 30 & 0.28 & 55.33 & $48.41 \pm 1.58^{\mathrm{a}}$ & $227.72 \pm 7.44^{\mathrm{abc}}$ & $25.95 \pm 0.85^{a}$ & $138.65 \pm 4.53^{\mathrm{a}}$ \\
\hline $10 \mathrm{~mm}$ & 50 & 0.24 & 49.33 & $46.51 \pm 1.52^{\mathrm{a}}$ & $205.58 \pm 6.71^{\mathrm{a}}$ & $36.80 \pm 1.2^{\mathrm{b}}$ & $157.42 \pm 5.14^{\mathrm{ab}}$ \\
\hline $10 \mathrm{~mm}$ & 70 & 0.16 & 41.33 & $47.21 \pm 1.54^{\mathrm{a}}$ & $213.09 \pm 6.96^{\mathrm{ab}}$ & $51.66 \pm 1.69^{c}$ & $156.40 \pm 5.11^{\mathrm{ab}}$ \\
\hline $10 \mathrm{~mm}$ & 90 & 0.12 & 38.33 & $49.68 \pm 1.62^{\mathrm{a}}$ & $217.18 \pm 7.09^{a b c}$ & $82.59 \pm 2.70^{d}$ & $175.28 \pm 5.72^{\mathrm{bc}}$ \\
\hline $8 \mathrm{~mm}$ & 30 & 0.27 & 48.00 & $50.59 \pm 1.65^{\mathrm{a}}$ & $207.46 \pm 6.78^{\mathrm{ab}}$ & $0.00 \pm 0$ & $186.12 \pm 6.08^{c d}$ \\
\hline $8 \mathrm{~mm}$ & 50 & 0.31 & 55.33 & $48.93 \pm 1.60^{\mathrm{a}}$ & $211.81 \pm 6.92^{\mathrm{ab}}$ & $0.00 \pm 0$ & $184.97 \pm 6.04^{\mathrm{cd}}$ \\
\hline $8 \mathrm{~mm}$ & 70 & 0.20 & 40.67 & $44.78 \pm 1.46^{\mathrm{a}}$ & $208.13 \pm 6.80^{\mathrm{ab}}$ & $0.00 \pm 0$ & $155.63 \pm 5.08^{\mathrm{ab}}$ \\
\hline $8 \mathrm{~mm}$ & 90 & 0.15 & 38.33 & $45.77 \pm 1.49^{a}$ & $207.75 \pm 6.79^{a b}$ & $75.21 \pm 2.46^{d}$ & $179.03 \pm 5.85^{c}$ \\
\hline $6 \mathrm{~mm}$ & 30 & 0.41 & 58.33 & $48.90 \pm 1.60^{\mathrm{a}}$ & $241.16 \pm 7.88^{c}$ & $43.14 \pm 1.41^{b}$ & $203.88 \pm 6.66^{\text {de }}$ \\
\hline $6 \mathrm{~mm}$ & 50 & 0.38 & 62.00 & $46.91 \pm 1.53^{\mathrm{a}}$ & $240.24 \pm 7.85^{c}$ & $40.82 \pm 1.33^{b}$ & $157.57 \pm 5.15^{a b}$ \\
\hline $6 \mathrm{~mm}$ & 70 & 0.33 & 63.67 & $49.51 \pm 1.62^{\mathrm{a}}$ & $239.54 \pm 7.82^{\mathrm{c}}$ & $116.72 \pm 3.81^{\mathrm{e}}$ & $221.58 \pm 7.24^{\mathrm{e}}$ \\
\hline Kernels & & $0.70^{1}$ & & 232.02 & $\pm 7.58^{\mathrm{b} / \mathrm{b} *}$ & 140.59 & $\pm 4.59^{\mathrm{f} / \mathrm{a} *}$ \\
\hline
\end{tabular}

Values are meanststandard deviations of a triplicate measurements. Alphabetical superscripts indicate significant differences ( $\mathrm{P}<0.05$ ) among values in columns. rpm: revolution per minute; TEA: trolox equivalent activity; GAE: gallic acid equivalent; ${ }^{1} \mathrm{~kg}$ of oil per $\mathrm{kg}$ of kernels determined by extraction with organic solvent (hexane); * letter/letter in superscript means statistical result among pressed oil/bagasse pellets

Higher antioxidant capacity in bagasse pellets can be contributed to high values of TPC (Gunduc and $\mathrm{El}, 2003)$, however, the lower but constant values of antioxidant capacity of pressed oils can be contributed to other compounds diluted in the oils such as tocopherols (Arranz et al., 2008).

\section{Fatty Acids Composition}

Linoleic, vaccenic, alfa-linolenic, palmitic and stearic acids were the predominant fatty acids in the kernels, pressed oil and the bagasse pellets (Tab. II and III), which confirms the results of Maguire et al. (2004).

The highest content of pressed oils and oils extracted from bagasse pellets was represented by polyunsaturated fatty acids (PUFA) which ranged from 71.75 to $72.24 \%$ (Tab. II) and from 71.85 to $72.64 \%$ (Tab. III), respectively, whereas the PUFA content in oil extracted from kernels represented $72.88 \%$, showing slightly higher value than of the PUFA in pressed oils and oils from bagasse pellets.

The monounsaturated fatty acids (MUFA) and saturated fatty acids (SFA) in pressed oil represented from 18.75 to 19.41\%; and 8.81 to $9.00 \%$, respectively, whereas the MUFA and SFA content in oil extracted from kernels was 18.40 and 8.71\%, respectively, showing lower values than MUFA and SFA content in pressed oil (Tab. II). The MUFA and SFA in oil extracted from bagasse pellets ranged from 17.96 to $19.20 \%$ and 8.86 to $9.06 \%$, respectively (Tab. III). Content of SFA in oils extracted from bagasse pellets was higher than of the oil extracted from the kernels. The same situation was observed at MUFA, however in oils extracted from bagasse pellets produced at $6 \mathrm{~mm}$ nozzle diameter at 50 and $70 \mathrm{rpm}$ the MUFA content was lower than of the oil extracted from kernels (Tab. III).

Eicosaenoic and eicosatetraenoic acids were the only fatty acids, where no significant differences were observed between pressed oil variants or oils extracted from bagasse pellets variants (Tabs. II and III). Except for the linoleic and alfa-linolenic acids, the concentrations of the other fatty acids in oil extracted from kernels were in the lower range than the concentrations of the same fatty acids in pressed oils and oils extracted from bagasse pellets.

\section{Relation of the Oil Pressing Temperature and Fatty Acid Content}

Correlation between the oil pressing temperature and the fatty acid content was calculated to stress out the influence of the temperature on the oil quality. Not all fatty acids showed significant correlation with the increasing oil pressing temperature. Among pressed oils, significant moderate positive correlation with oil pressing temperature was observed at palmitic (0.513) and adrenic (0.456) acid and significant moderate negative correlation at linoleic acid (-0.581) (Tab. IV).

Higher number of significant correlations were observed at oils extracted from bagasse pellets, where significant positive moderate correlation was observed at myristic (0.691), palmitoleic (0.501), stearic (0.678), vaccenic (0.579), gamma-linolenic (0.509), eicosaenoic (0.539) and adrenic (0.680) acid and significant negative moderate correlation was 


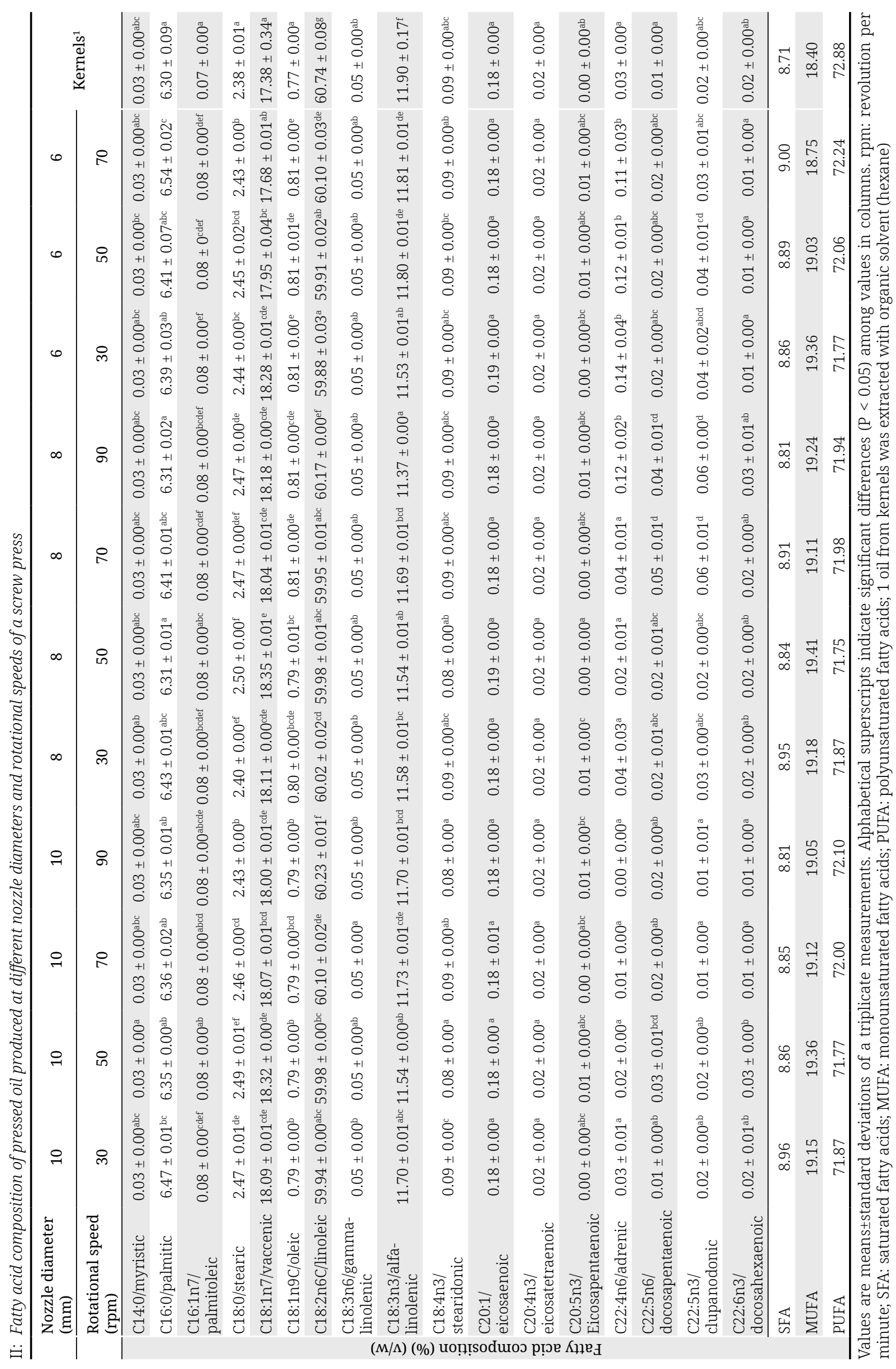




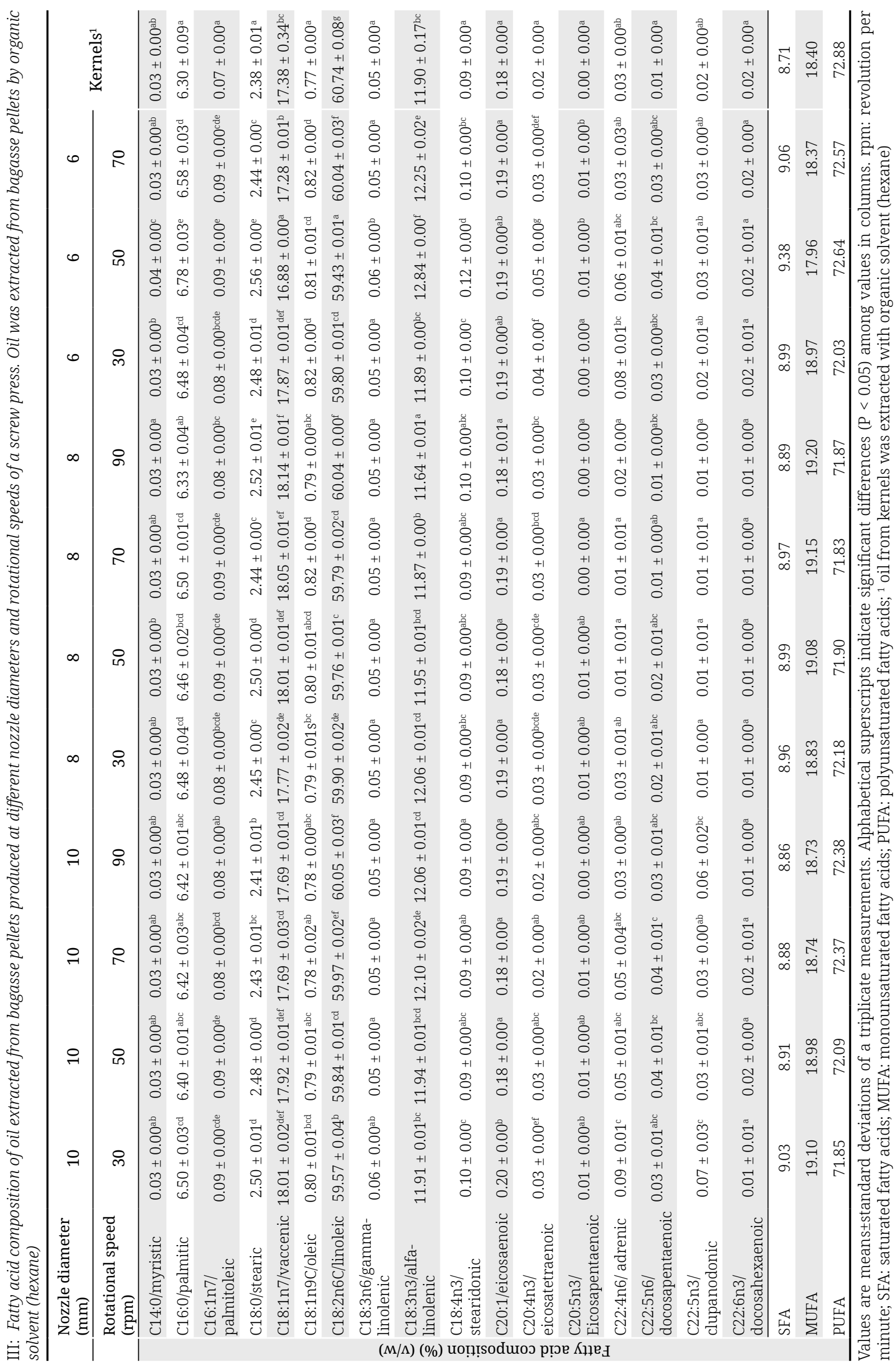


IV: Correlation coefficients between fatty acids of pressed oils/bagasse pellets and oil pressing temperatures

\begin{tabular}{lcc}
\hline \multicolumn{1}{c}{ Fatty acid } & Pressed oil $^{1}$ Bagasse pellets $^{2}$ \\
\hline C14:0/myristic & 0.405 & $0.691^{*}$ \\
C16:0/palmitic & $0.513^{*}$ & 0.342 \\
C16:1n7/palmitoleic & 0.422 & $0.501^{*}$ \\
C18:0/stearic & -0.195 & $0.678^{*}$ \\
C18:1n7/vaccenic & -0.210 & $0.579^{*}$ \\
C18:1n9C/oleic & 0.266 & 0.428 \\
C18:2n6C/linoleic & $-0.581^{*}$ & $-0.547^{*}$ \\
C18:3n6/gamma-linolenic & 0.168 & $0.509^{*}$ \\
C18:3n3/alfa-linolenic & 0.352 & $-0.528^{*}$ \\
C18:4n3/stearidonic & 0.303 & 0.338 \\
C20:1/eicosaenoic & 0.095 & $0.539^{*}$ \\
C20:4n3/eicosatetraenoic & 0.360 & 0.440 \\
C20:5n3/eicosapentaenoic & 0.017 & -0.109 \\
C22:4n6/adrenic & $0.456^{*}$ & $0.680^{*}$ \\
\hline C22:5n6/docosapentaenoic & -0.358 & 0.332 \\
\hline C22:5n3/clupanodonic & -0.089 & 0.381 \\
C22:6n3/docosahexaenoic & -0.225 & 0.195 \\
\hline SFA & $0.507^{*}$ & $0.709^{*}$ \\
\hline MUFA & -0.189 & $-0.515^{*}$ \\
\hline PUFA & 0.103 & 0.312 \\
\hline Asteisk & \\
\hline
\end{tabular}

Asterisk indicates statistical significant correlation $(\mathrm{P}<0.05)$. SFA: saturated fatty acids; MUFA: monounsaturated fatty acids; UFA: polyunsaturated fatty acids; ${ }^{1}$ oil extracted by pressing in the screw press; ${ }^{2}$ oil extracted from bagasse pellets by organic solvent (hexane) observed only at linoleic (-0.547) and alfa-linolenic $(-0.528)$ acid (Tab. IV).

SFA in pressed oils and oils extracted from bagasse pellets showed significant moderate and strong positive correlation, respectively, with oil pressing temperature (Tab. IV), showing, that the content of SFA was increasing with higher temperatures. PUFA showed positive correlation with oil pressing temperatures, however, the correlation coefficients were not significant and were lower than correlation coefficients of the SFA (Tab. IV). According to Sobajic and Gajic-Krstajic (2011), the PUFA are more prone to degradation than MUFA, however, in our study significant moderate negative correlation was observed at MUFA at oils extracted from bagasse pellets and nonsignificant moderate at pressed oil (Tab. IV), showing that MUFA were negatively influenced by higher temperatures during pressing.

Although the bagasse pellets had higher values of antioxidant capacity than pressed oils, indicating better protection of the fatty acids (Fukuda et al., 2003), higher number of significant correlations and values of correlation coefficients was shown in oils extracted from bagasse pellets when compared to pressed oils (Tab. IV). Therefore, if the bagasse pellets will be used as food resources, it should be kept in mind that the fatty acids in bagasse pellets are more affected by higher temperatures than in pressed oil.

\section{CONCLUSION}

The separation ability of the press affected the antioxidant capacity and TPC of either bagasse pellets and pressed oil. Higher values of antioxidant capacity and TPC were measured in bagasse pellets than in pressed oils. Nozzle diameter affected the antioxidant capacity in bagasse pellets, however, not in pressed oil. Rotational speed did not affect antioxidant capacity in pressed oil, nor in bagasse pellets. Higher amount of pressed oil was yielded by using lower nozzle diameter, indicating better oil/bagasse separation, and resulted in higher concentration of phenolic compounds and antioxidant capacity than at higher nozzle diameters. However, by lowering the nozzle diameter the oil pressing temperature was rising, which affected the fatty acids. Positive correlations with oil pressing temperatures were calculated at SFA, while the correlation coefficients of polyunsaturated fatty acids were positive, but not significant. MUFA were negatively affected by higher oil pressing temperatures showing, that MUFA were more susceptible to higher temperatures than PUFA and SFA. Therefore, when considering the fatty acid content, higher temperatures during pressing should be avoided, especially when considering the use of bagasse pellets where the fatty acids were more affected by higher temperatures than in the pressed oil.

\section{Acknowledgements}

This paper was finalized and supported by the project IGA-ZF/2019-AP001 "The development and verification of products obtained from the fruit species oil seeds pressing intended for use in the cosmetic and food industry" and by the project CZ.02.1.01/0.0/0.0/16_017/0002334 Research Infrastructure for Young Scientists, co-financed by Operational Programme Research, Development and Education. 


\section{REFERENCES}

ARRANZ, S. et al. 2008. Comparison between free radical scavenging capacity and oxidative stability of nut oils. Food Chemistry, 110(4): 985-990.

AVANZATO, D. 2009. Traditional and Modern Uses of Walnut. Acta Horticulturae, 861: 89-96.

BAKKALBASI, E., MERAL, R. and DOGAN, I. S. 2015. Bioactive Compounds, Physical and Sensory Properties of Cake Made with Walnut Press-Cake. Journal of Food Quality, 38(6): 422-430.

BURG, P., MAŠÁN, V. and RUTKOWSKI, K. et al. 2017. Seed oil content and selected qualitative parameters of oils from grape seeds. Potravinarstvo, 11(1): 629-633.

EZEH, O., GORDON, M. H. and NIRANJAN, K. 2016. Enhancing the recovery of tiger nut (Cyperus esculentus) oil by mechanical pressing: Moisture content, particle size, high pressure and enzymatic pre-treatment effects. Food Chemistry, 194: 354-361.

FAO. 2016. FAOSTAT database collections. [Online]. Food and Agriculture Organization of the United Nations. Available at: http://faostat.fao.org. [Accessed: 2018, February 7].

FUKUDA, T., ITO, H. and YOSHIDA, T. 2003. Antioxidative polyphenols from walnuts (Juglans regia L.). Phytochemistry, 63(7): 795-801.

GHARIBZAHEDI, S. M. T. et al. 2013. Evaluation of physicochemical properties and antioxidant activities of Persian walnut oil obtained by several extraction methods. Industrial Crops and Products, 45: 133-140.

GUNDUC, N. and EL, S. N. 2003. Assessing Antioxidant Activities of Phenolic Compounds of Common Turkish Food and Drinks on In Vitro Low-Density Lipoprotein Oxidation. Journal of Food Science, 68(8): 2591-2595.

HOU, L. Q. et al. 2013. Analysis of major nutrient compositions in kernel of 'Jizhaomian' walnut. Acta Horticulturae, 1050: 69-74.

KAUR, R., KAUR, U. and WALIA, H. 2015. Evaluation of Free Radical Scavenging Activities of Aqueous Extracts of Fruits of Ziziphus mauritiana and Eriobotrya japonica Through in vitro Antioxidant Assays. Global Journal of Research and Rewiew, Bhopal, 2(1): 30-36.

KENDALL, C. W. C. et al. 2011. The glycemic effect of nut-enriched meals in healthy and diabetic subjects. Nutrition, Metabolism and Cardiovascular Diseases, 21: S34-S39.

KODAD, O. et al. 2016. Genotype and year variability of the chemical composition of walnut oil of Moroccan seedlings from the high Atlas Mountains. Grasas y Aceites, 67(1): 116.

LABUCKAS, D., MAESTRI, D. and LAMARQUE, A. 2014. Effect of different oil extraction methods on proximate composition and protein characteristics of walnut (Juglans regia L.) flour. LWT-Food Science and Technology, 59(2): 794-799.

LING, B. et al. 2016. Physicochemical properties, volatile compounds, and oxidative stability of cold pressed kernel oils from raw and roasted pistachio (Pistacia vera L. var Kerman). European Journal of Lipid Science and Technology, 118(9): 1368-1379.

MAGUIRE, L. S. et al. 2004. Fatty acid profile, tocopherol, squalene and phytosterol content of walnuts, almonds, peanuts, hazelnuts and the macadamia nut. International Journal of Food Sciences and Nutrition, 55(3): 171-178.

MARTINEZ, M. L., MATTEA, M. A. and MAESTRI, D. M. 2006. Varietal and crop year effects on lipid composition of walnut (Juglans regia) genotypes. Journal of the American Oil Chemists' Society, 83(9): 791-796.

MRIDULA, D., BARNWAL, P. and SINGH, K. K. 2015. Screw pressing performance of whole and dehulled flaxseed and some physico-chemical characteristics of flaxseed oil. Journal of Food Science and Technology, 52(3): 1498-1506.

ÖZCAN, M. M. 2009. Some nutritional characteristics of fruit and oil of walnut (Juglans regia L.) growing in Turkey. Iranian Journal of Chemistry and Chemical Engineering (IJCCE), 28(1): 57-62.

SENA-MORENO, E. et al. 2016. Differences in oils from nuts extracted by means of two pressure systems. International Journal of Food Properties, 19(12): 2750-2760.

SINGH, J. and BARGALE, P. C. 2000. Development of a small capacity double stage compression screw press for oil expression. Journal of Food Engineering, 43(2): 75-82.

SLATNAR, A. et al. 2015. Identification and quantification of phenolic compounds in kernels, oil and bagasse pellets of common walnut (Juglans regia L.). Food Research International, 67: 255-263.

SOBAJIC, S. and GAJIC-KRSTAJIC, L. 2011. Determination of fatty acid and tocopherol compositions and the oxidative stability of walnut (Juglans regia L.) cultivars grown in Serbia. Czech J. Food Sci., 29(1): 74-78.

PARK, S. K. et al. 2008. a-and $\gamma$-Tocopherol prevent age-related transcriptional alterations in the heart and brain of mice. The Journal of Nutrition, 138(6): 1010-1018.

POGGETTI, L. et al. 2018. Kernel oil content and oil composition in walnut (Juglans regia L.) accessions from north-eastern Italy. Journal of the Science of Food and Agriculture, 98(3): 955-962. 
UZUNOVA, G. et al. 2015. Chemical composition of walnut oil from fruits on different years old branches. Bulgarian Journal of Agricultural Science, 21(3): 494-497.

WANG, Q. 2016. Peanuts: processing technology and product development. Boston, MA: Elsevier.

ZWARTS, G. P., SAVAGE, D. L. and MCNEIL, L. 1999. Fatty acid content of New Zealand-grown walnuts (Juglans regia L.). International Journal of Food Sciences and Nutrition, 50(3): 189-194.

Contact information

Tomáš Kiss: tomas.kiss@mendelu.cz

Vladimír Mašán: vladimir.masan@mendelu.cz

Pavel Híc: pavel.hic@mendelu.cz 